\title{
Correction to: Uranium speciation in coal fragments of radioactively contaminated soil
}

\author{
Anna $\operatorname{Krot}^{1}\left[\mathbb{D} \cdot\right.$ Irina Vlasova ${ }^{1} \cdot$ Alexander Trigub $^{2}$
}

Published online: 3 February 2022

(c) The Author(s), under exclusive licence to The MaterialsResearch Society 2022

\section{Correction to: MRS Advances \\ https://doi.org/10.1557/s43580-022-00211-8}

This article was updated to fix a typographical error in the abstract.

Publisher's Note Springer Nature remains neutral with regard to jurisdictional claims in published maps and institutional affiliations.

The original article can be found online at https://doi.org/10.1557/ s43580-022-00211-8.

Anna Krot

anna.d.krot@gmail.com

Irina Vlasova

irinaeng@gmail.com

Alexander Trigub

alexander.trigub@gmail.com

1 Lomonosov Moscow State University, Moscow, Russia

2 National Research Center «Kurchatov Institute», Moscow, Russia 